\title{
Quantification of sigma-phase evolution in thermally aged 2205 duplex stainless steel
}

\author{
A. D. Warren ${ }^{1}$ R. L. Harniman ${ }^{2}$ - Z. Guo ${ }^{3}$ C. M. Younes ${ }^{1}$ - P. E. J. Flewitt ${ }^{1,4}$ • \\ T. B. Scott ${ }^{1}$
}

Received: 20 February 2015/Accepted: 25 May 2015/Published online: 3 November 2015

(C) The Author(s) 2015. This article is published with open access at Springerlink.com

\begin{abstract}
In this study, the evolution of sigma-phase development in a 2205 duplex steel was studied following thermal ageing in the temperature range $750-850{ }^{\circ} \mathrm{C}$ for periods up to $100 \mathrm{~h}$. A suite of materials analysis techniques including combined electron backscatter diffraction-energy-dispersive X-ray imaging and magnetic force microscopy are used to quantify the change in volume fraction of the phases. The experimental results for each ageing condition are compared with the results from other ageing experiments and the predictions from the computer modelling. They show good correlation for the amount of sigma phase formed under a range of ageing conditions (and thus varying quantities of sigma phase). EBSD measurements showed no preferential orientation relationships relative to the parent ferrite for the nucleation of sigma phase, implying that the minimisation of boundary misorientation energy is not significant in determining sigma-phase nucleation sites. The results are discussed with respect to the experimentally measured properties of sigma phase and the kinetics of the precipitation process.
\end{abstract}

A. D. Warren

aw6313@bristol.ac.uk; Xander.Warren@bristol.ac.uk

1 Interface Analysis Centre, HH Wills Laboratory, University of Bristol, Bristol BS8 1FD, UK

2 School of Chemistry, University of Bristol, Bristol BS8 1TS, UK

3 Sente Software Ltd, Surrey Technology Centre, Guildford GU2 7YG, UK

4 School of Physics, HH Wills Laboratory, University of Bristol, Bristol BS8 1FD, UK

\section{Introduction}

Duplex steels contain a mixture of both austenite and $\delta$ ferrite which typically imbues beneficial mechanical properties compared with traditional austenitic stainless and high-alloy ferritic steels. Following appropriate heat treatments, these steels exhibit a good combination of strength and fracture toughness $[1,2]$ and, in addition, retain a high level of resistance to intergranular corrosion [1-3]. As such, duplex steels are frequently adopted for components and structures used in a range of industries [4]. However, in situations where the components or structures are subjected to prolonged service at higher temperatures or thermal cycling, these steels are prone to the formation of additional phases [1,4], which often degrade the physical, chemical and mechanical properties [4], e.g. the formation of sigma phase during the thermal ageing of duplex steels under a range of conditions [2-5]. It is associated with embrittlement $[1,4,5]$ and loss of corrosion resistance $[4,5]$, and as such can be severely damaging to the overall structural integrity of a component fabricated from these steels.

Both $\mathrm{Cr}$ and Mo alloying elements are observed to concentrate in ferrite, where they have a greater rate of diffusion, so sigma precipitation from bcc ferrite is preferable compared to fcc austenite $[4,5]$. Sigma phase is an iron-chrome-molybdenum intermetallic phase, formed at high temperature $\left(600-900{ }^{\circ} \mathrm{C}\right)$. It has a tetragonal symmetry point group with 30 atoms per unit cell [6]. During sigma-phase formation, a significant decrease in Mo content within the adjacent ferrite has been observed [5]. As the rate of $\mathrm{Cr}$ diffusion is approximately half that for the Mo atoms in ferrite at $900{ }^{\circ} \mathrm{C}$ [5], it is possible that the depletion of Mo in ferrite is due to the more rapid diffusion of these atoms. However, the diffusion of $\mathrm{Cr}$ and 
Mo within the ferrite matrix to form sigma-phase precipitates also causes simultaneous local transformation to austenite due to the attendant enrichment in elements such as Ni $[1,2,4,7]$. The co-formation of austenite often leads to the sigma phase forming what is described as a $3 \mathrm{D}$ 'lacey' interconnected microstructure [7].

Several previous experimental studies undertaken on 2205 duplex stainless steel have considered the role of thermal ageing, in particular, for short periods of time $(<20 \mathrm{~h})$ at temperatures in the range $350-900{ }^{\circ} \mathrm{C}$ on the precipitation processes $[2,3,5]$ and the associated mechanical properties $[2,3]$. One physical method for determining the evolution of sigma phase is to measure magnetically the change in the volume fraction of ferrite [8]. There are several other techniques that have been used to distinguish between the various phases, such as electron backscatter diffraction (EBSD) and X-ray diffraction spectroscopy (XRD) [9-11]. The results obtained are often dependant on the volume of the sampled region, and thus in many cases the volume fraction of each phase measured will differ between techniques. Magnetic force microscopy (MFM) is a variant of atomic force microscopy (AFM) [12] which uses a magnetic probe tip to map in 2D the distribution of the magnetic domains present at the surface of a specimen $[13,14]$. As ferrite is ferromagnetic, and austenite and sigma phase are paramagnetic $[15,16]$, it is possible to use this magnetic interaction to differentiate between the phases. The technique has previously been used to undertake an analysis of the magnetic properties of the ferrite bands in duplex steels [17-19], however, these workers have not used the technique to characterise the distribution and volume fraction of various phases in the overall microstructure. Recently, Warren et al. [20] have compared EBSD with MFM for the quantification of ferrite in Type 321 stainless steel. It was found that the distribution of ferrite mapped by each technique showed a very good correlation. However, MFM has a sub-surface measurement sensitivity so that it consistently over estimated the area fraction of ferrite, unless a correction factor was applied. Since MFM is not able to detect sigma phase, it is reliant on using the reduction in the proportion of ferrite as ageing progresses, to allow a measure of the evolution of sigma phase to be derived.

Chi phase is a paramagnetic BCC intermetallic phase [21] (composition ranging from $\left(\mathrm{Fe}, \mathrm{Ni}_{36} \mathrm{Cr}_{12} \mathrm{Mo}_{10}\right.$ to $(\mathrm{Fe}$, Ni) ${ }_{36} \mathrm{Cr}_{12} \mathrm{Mo}_{3} \mathrm{Ti}_{7}$ [21-25]) observed to nucleate in duplex steels following short ageing periods at high temperatures (e.g. $2 \mathrm{~h} / 700{ }^{\circ} \mathrm{C}$ [22], $1 \mathrm{~h} / 750{ }^{\circ} \mathrm{C}$ [22], $2 \mathrm{~h} / 750{ }^{\circ} \mathrm{C}$ [26], $30 \mathrm{~min} / 780{ }^{\circ} \mathrm{C}$ [27] and $30 \mathrm{~min} / 800{ }^{\circ} \mathrm{C}$ [28] ). Although the formation of chi phase in duplex steels is often initially favoured over that of sigma phase, sigma-phase formation is favoured over longer ageing periods [27] with chi phase having been observed to transform into sigma phase following further ageing [22, 26, 27].
In this paper, both the nucleation and growth of the sigma phase are predicted for a range of ageing conditions. The evolving microstructure was quantified experimentally with MFM and EBSD. The results are compared with each other, and the predicted phase volume percentages and activation energies are discussed. The capability of the techniques to explore differences between the assumed mechanism used for the computer model and the observed mechanism for sigma-phase evolution is discussed, including the role of preferred orientation on sigma-phase nucleation.

\section{Materials and methods}

The steel used in this study was Outokumpu 2205 duplex stainless steel, received in the hot-rolled condition, and Table 1 gives the chemical composition. Specimens of approximately $10 \mathrm{~mm} \times 10 \mathrm{~mm}$ by $5 \mathrm{~mm}$ were aged at $800{ }^{\circ} \mathrm{C}$ for periods of $1 / 2,1,3,5,10,20,40$ and $100 \mathrm{~h}$ in an argon atmosphere before being furnace cooled. All the specimens were consecutively polished with silicon carbide papers and diamond pastes to obtain a $0.25 \mu \mathrm{m}$ surface finish. Further polishing with $0.1 \mu \mathrm{m}$ colloidal silica for a period of $24 \mathrm{~h}$ was used to obtain a $15 \mathrm{~nm}$ root mean square surface roughness which was suitable for both EBSD and MFM evaluation.

Magneprobe "ferrite meters" are a modification of a Hall probe where the system uses the pre-defined magnetic permeability of ferrite to determine the quantity (vol\%) of that phase present in the sample volume [11]. Magneprobe measurements were recorded from four locations on the surface (approximately $1 \mathrm{~mm}$ dia.) for each specimen. The probe was calibrated against materials of a known ferrite content prior to, and after measurement with a maximum variation of $\pm 0.015 \mathrm{vol} \%$, which was observed with the lowest ferrite content standard $(0.54 \mathrm{vol} \%)$. The error given is based on the range from three repeat measurements in the same location. No specific sample preparation was required for these measurements.

EBSD analysis was performed in a Zeiss EVO MA10 scanning electron microscope (SEM) fitted with a $\mathrm{LaB}_{6}$ electron source and a high-speed camera (DigiView 3). The EBSD scans were performed by operating the SEM at $30 \mathrm{kV}$ with the secondary electron imaging mode. The specimen was tilted by $70^{\circ}$ to the horizontal, and EBSD maps were acquired using a step size of $1 \mu \mathrm{m}$. Orientation image mapping (OIM) data collection software (Ametek, Utah, USA) was used to analyse the EBSD maps which were subjected to a confidence index thresholding, and data points with a confidence of less than $10 \%$ were removed. The EBSD area fractions of phases were observed from the mean of three measurements. Phase quantification in EBSD 
Table 1 Composition of Outokumpu 2205 duplex stainless steel (wt\%)

\begin{tabular}{llllllllllll}
\hline $\mathrm{C}$ & $\mathrm{Si}$ & $\mathrm{Mn}$ & $\mathrm{P}$ & $\mathrm{S}$ & $\mathrm{Cr}$ & $\mathrm{Ni}$ & $\mathrm{Mo}$ & $\mathrm{N}$ & $\mathrm{Cu}$ & $\mathrm{Ti}$ & $\mathrm{Ce}$ \\
\hline 0.016 & 0.39 & 1.43 & 0.022 & 0.001 & 22.39 & 5.7 & 3.19 & 0.178 & 0.2 & 0.001 & 0.002 \\
\hline
\end{tabular}

maps is given by the percentage of pixels of a phase, following the removal of points with $<10 \%$ confidence index.

The atomic force microscope (AFM) used for MFM measurements was a Bruker Multimode microscope with a Nanoscope V controller and Picoforce extender, fitted with a Budget Sensors Multi 75 M-G tip (Innovative Solutions Bulgaria Ltd., Sofia, Bulgaria) of 'high' coercivity. As described elsewhere for ferrite evaluation [20], the optimum settings for imaging were determined to be a lift height of $50 \mathrm{~nm}$, drive amplitude-based noise reduction, a step size of $170 \mathrm{~nm}$ and a scan rate of $0.54 \mathrm{~Hz}$. The AFM/MFM data were analysed with the Gwyddion 2.30 [29] open source scanning probe microscopy analysis software (http://gwyd dion.net/; Czech Metrology Institute, Brno, Czech Republic). Data processing used the procedure detailed previously [20], and ferrite quantification used a combined manual and automated thresholding procedure. Where area fractions are presented, they have been calculated using the previously determined [20] correction factor, 0.97. Although MFM and Magneprobe are both magnetic detection techniques, the two techniques differ significantly in the type of data collected. Magneprobe gives a bulk measure of the ferrite content within a $\sim 1 \mathrm{~mm}^{3}$ volume of material, whilst MFM is a near-surface mapping technique more comparable to EBSD. Both techniques are only sensitive to ferromagnetic phases, and as such MFM maps the spatial distribution of ferrite as well as providing quantification.

\section{Model predictions}

Since the nucleation and growth of sigma-phase precipitation is a diffusion-controlled process, where the kinetics can be described using a Johnson-Mehl-Avrami type (JMA) model [30-36], the process has been modelled into two parts. The first is the thermodynamic calculation based on the CALPHAD approach [34], and this is particularly important when dealing with multi-component systems. Such thermodynamic calculations provide information addressing phase equilibrium and phase volume fraction as well as accounting for the driving force. The second is the application of the JMA [34] kinetic model, using the calculated thermodynamic information as inputs. The developed computer model has been implemented in JMatPro $[33,34,37]$, and has been previously used to predict the evolution of sigma phase [33] with the linked comparison with the expected evolution of the microstructure of a 2205 duplex stainless steel.
The computer model used to make predictions of the expected evolution of sigma phase during the thermal ageing of the 2205 duplex stainless steel in the temperature range 750,800 and $850^{\circ} \mathrm{C}$ was JMatPro (Sente Software, Surrey, UK) [33, 34]. Further details on the model are given by Li et al. [33]. Sieurin and Sandström [5] presented a JMA composition model to predict the growth of sigma precipitates in a 2205 duplex stainless steel with a differing treatment of nucleation and growth compared to JMatPro. These calculations report a satisfactory agreement with the JMatPro predictions, and such a comparison has not been undertaken in this study.

The predicted volume fraction of sigma phase under isothermal ageing conditions at $750-850{ }^{\circ} \mathrm{C}$ for periods of up to $100 \mathrm{~h}$, using the composition for the specific 2205 duplex steel (Table 1), is given in Table 2 and shown in Fig. 1. The reaction pathway used considered the co-formation of $\mathrm{Cr} / \mathrm{Mo}$-depleted austenite, and complete consumption of ferrite once the material had reached equilibrium: $\delta$-ferrite $\rightarrow \sigma+$ secondary austenite. Note the equilibrium behaviour is such that the maximum volume fraction of sigma phase will be formed at approximately $750{ }^{\circ} \mathrm{C}$-thus, the total volume fraction of sigma phase formed during ageing at 800 and $850{ }^{\circ} \mathrm{C}$ is expected to be marginally lower than that formed at $750{ }^{\circ} \mathrm{C}$, although the higher temperatures will give a faster rate of growth.

\section{Results}

The unaged material shows the lamellar bands of austenite and ferrite typical of duplex steels, containing approximately $49 \%$ ferrite. The experimentally collected phase data show that during ageing the sigma-phase evolution process occurs through the eutectoid decomposition of ferrite $\rightarrow$ sigma + secondary austenite, which correlates well with literature observations $[2-4,8]$. Table 3 summarises the percentage of ferrite measured by the three techniques for the selected temperature of $800{ }^{\circ} \mathrm{C}$. These data are plotted in Fig. $2 \mathrm{a}$ and the corresponding sigmaphase data are plotted in Fig. 2b. It was not possible to rapidly and effectively distinguish between ferrite and chi phase with EBSD, as the BCC crystal structures of these phases typically gave a small difference in the confidence of phase identification. Low confidence index points have been removed in an attempt to remove chi-phase precipitates which have erroneously been identified as ferrite, 
Table 2 JMatPro model predictions of the evolution of sigma phase (\%) during ageing at 750,800 and $850{ }^{\circ} \mathrm{C}$

\begin{tabular}{|c|c|c|c|c|c|c|c|c|c|}
\hline Ageing duration (h) & $1 / 2$ & 1 & 3 & 5 & 10 & 20 & 40 & 50 & 100 \\
\hline Volume fraction of Sigma for ageing at $750{ }^{\circ} \mathrm{C}(\%)$ & 1.2 & 2.5 & 6.5 & 9.1 & 12.9 & 16.3 & 18.7 & 19.2 & 19.5 \\
\hline Volume fraction of Sigma for ageing at $800{ }^{\circ} \mathrm{C}(\%)$ & 3.1 & 5.7 & 11.6 & 14.0 & 17.1 & 19.0 & 19.0 & 19.0 & 19.0 \\
\hline Volume fraction of Sigma for ageing at $850{ }^{\circ} \mathrm{C}(\%)$ & 5.8 & 9.1 & 15.0 & 17.0 & 18.8 & 19.0 & 19.0 & 19.0 & 19.0 \\
\hline
\end{tabular}

Fig. 1 Comparison plot between the JMatPro predictions for the evolution of percentage of sigma phase during ageing at 750,800 and $850{ }^{\circ} \mathrm{C}$, and the experimental observations. Lines are shown to emphasise the trends in the volume fraction of the phases. The predicted sigma-phase line is based on the predictions at the points shown, and does not correspond to a full range prediction
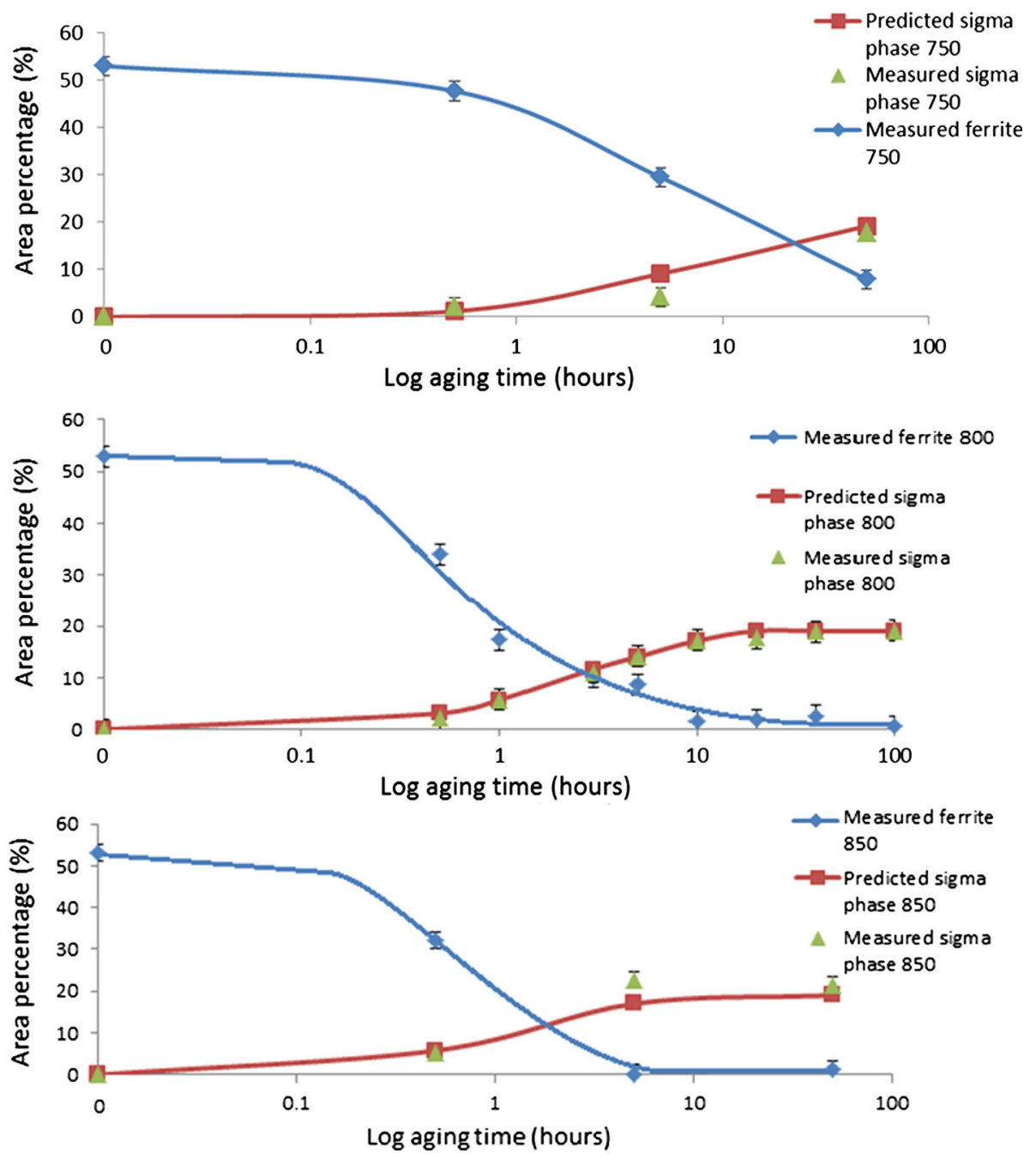

however, this is not expected to be completely effective. As such, EBSD ferrite measurements may include a low volume percentage of chi phase. Errors on the EBSD measurements are the maximum deviation from a mean taken from multiple maps of different regions, all of which have had the low confidence index points removed. As such, the area fraction presented is the maximum.

As chi phase is paramagnetic, it will not be included in the MFM ferrite measurements. Error on the MFM values arises from how accurately the thresholding captures the recorded ferrite-in this case, quantification is performed multiple times, the mean taken and the highest deviation given.

The potential influence of chi phase on the EBSD data was assessed by comparing EBSD phase and MFM maps for the same region. BCC 'ferrite' grains in the EBSD data which were mapped as paramagnetic in the MFM would thus be chi phase. Figure 3 shows these comparisons for an unaged specimen and a specimen aged for $30 \mathrm{~min}$ at $800{ }^{\circ} \mathrm{C}$, conditions under which chi phase has been 
Table 3 Summary of ferrite and sigma measurements for 2205 duplex steel aged at $800{ }^{\circ} \mathrm{C}$

\begin{tabular}{llllllllll}
\hline Ageing duration (h) & 0 & $1 / 2$ & 1 & 3 & 5 & 10 & 20 & 40 & 100 \\
\hline Magneprobe (vol\% ferrite) & 46.8 & 27.2 & 11.6 & 6.5 & 5.2 & 4.3 & 2.2 & 1.0 \\
MFM (Area \% ferrite) & $47 \pm 3$ & $39 \pm 3$ & $30 \pm 5$ & $7.9 \pm 3$ & $13.3 \pm 4$ & $9.2 \pm 2$ & $3.4 \pm 3$ & $4.7 \pm 1$ & 0.28 \\
EBSD (Area \% ferrite) & $53 \pm 1$ & $34 \pm 11$ & 17.3 & $10 \pm 0.8$ & 8.6 & 1.6 & $1.9 \pm 1$ & $2.6 \pm 0.7$ & $0.6 \pm 0.6$ \\
EBSD (Area \% SIGMA) & 0 & 5.4 & 7.7 & 11.3 & 10.0 & 12.6 & 15.8 & 17.0 & 13.7
\end{tabular}

As can be seen after 10-20 h the majority of the ferrite present has been consumed. This leads to an increased error on the area percentage measurements for periods over $10 \mathrm{~h}$ for many techniques due to a combination of regional discrepancies and the comparatively small sample area

Fig. 2 Graphical representations showing the experimentally measured phase changes during ageing at $800{ }^{\circ} \mathrm{C}$. a Shows the consumption of ferrite over the entire ageing period and $\mathbf{b}$ the evolution of sigma phase across the whole ageing period. Lines are shown to emphasise the trends in the volume percentage of the phases
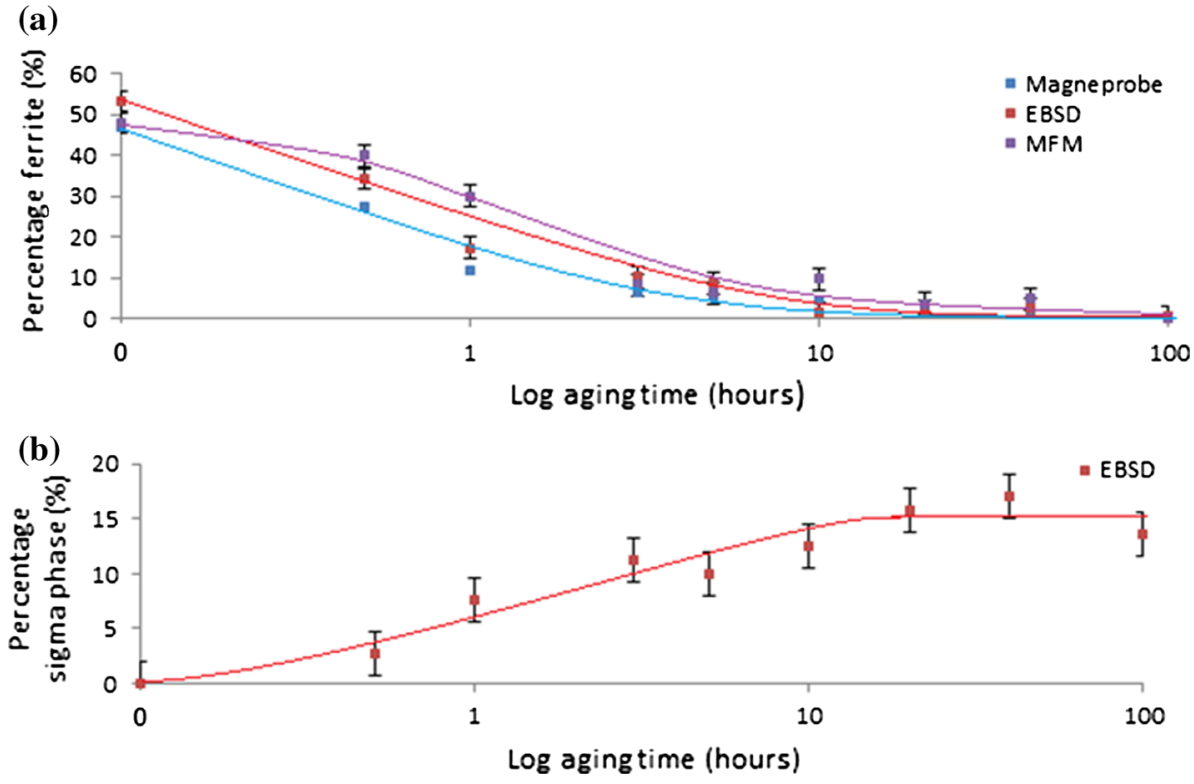

observed previously [27, 28]; there are no chi-phase precipitates observed. Similar comparisons were performed for material aged for up to $3 \mathrm{~h}$ at $800{ }^{\circ} \mathrm{C}$, again with no chiphase precipitates observed.

Above $10 \mathrm{~h}$ ageing, both EBSD and MFM techniques show significant sampling variation, with some areas giving quantities of ferrite which would more typically be associated with much lower ageing periods and yet with ferrite being effectively absent in other maps. At these volume fractions, the depth sensitivity of MFM becomes a more significant factor, as it is possible to detect grains which were entirely hidden from surface techniques such as EBSD [20]. Given the high volume fraction (15-20\%) of sigma phase such fluctuations were less statistically significant.

Two further ageing conditions $\left(750\right.$ and $\left.850{ }^{\circ} \mathrm{C}\right)$ were investigated for a more limited range of ageing periods to test the correlation between experimental results and computer model predictions, additionally enabling the determination of the rate of reaction for the formation of sigma phase during ageing, for comparison with that used in the JMatPro predictions. The experimentally determined and predicted phase area percentages are given in Table 4.

Throughout the ageing up to $100 \mathrm{~h}$, there is a partial preservation of the lamellar banded structure at $800{ }^{\circ} \mathrm{C}$, Fig. 4. The EBSD phase maps show the microstructure prior to ageing and then following exposure for 1 and $100 \mathrm{~h}$. The red is austenite, the green is ferrite and yellow is sigma phase (the black regions are where low confidence data have been removed).

A typical sigma-phase distribution can be observed in the $1 \mathrm{~h}$ aged EBSD phase map, Fig. 4b. This is traditionally associated with diffusional growth [4, 7], which is supported by the change of the precipitate sizes during ageing. The mean sigma precipitate size remains fairly constant $\left(6.5-8.4 \mu \mathrm{m}\right.$ diameter/30-55 $\left.\mu^{2}\right)$ as does the standard deviation (approximately $5.5 \mu \mathrm{m}$ dia. $/ 23 \mu \mathrm{m}^{2}$ ), although the maximum precipitate size increases with prolonged ageing. The mean size of ferrite grains falls as ageing continues, from an initial size of approximately $26.5 \mu \mathrm{m}$ dia. $/ 535 \mu^{2}$ to approximately $20.5 \mu \mathrm{m}$ dia./ $330 \mu^{2}$ after $1 \mathrm{~h}$ of ageing, and then to approximately 


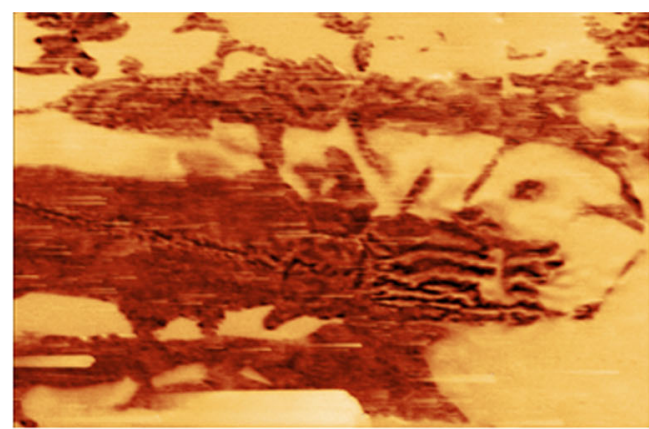

(a)

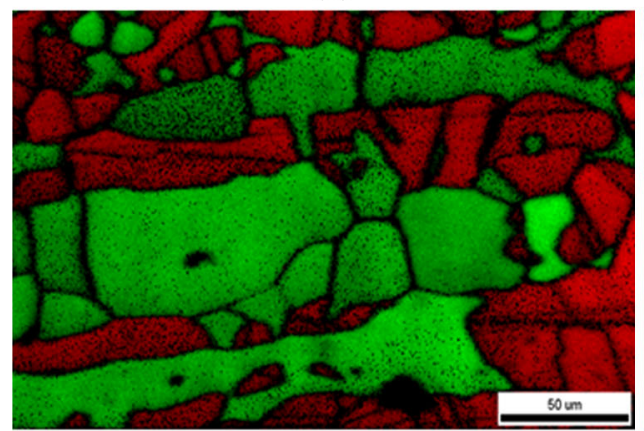

(c)

Fig. 3 Comparison images of MFM magnetic maps versus their corresponding EBSD phase maps for thermally aged 2205 duplex steels. $\mathbf{a}$ and $\mathbf{c}$ are from an unaged specimen, whilst $\mathbf{b}$ and $\mathbf{d}$ are from a specimen aged at $800{ }^{\circ} \mathrm{C}$ for $30 \mathrm{~min}$. a and $\mathbf{b}$ MFM maps-the dark

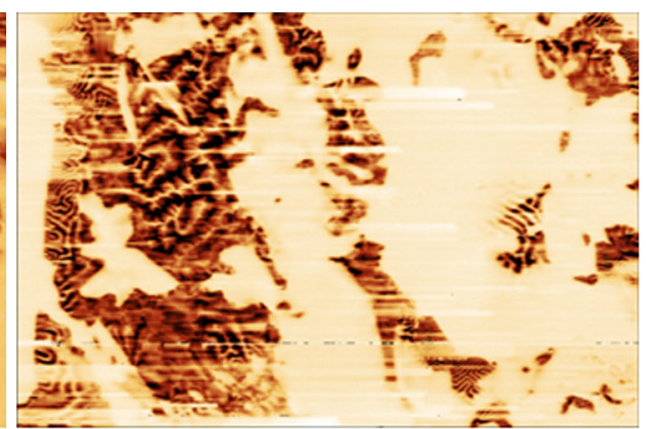

(b)

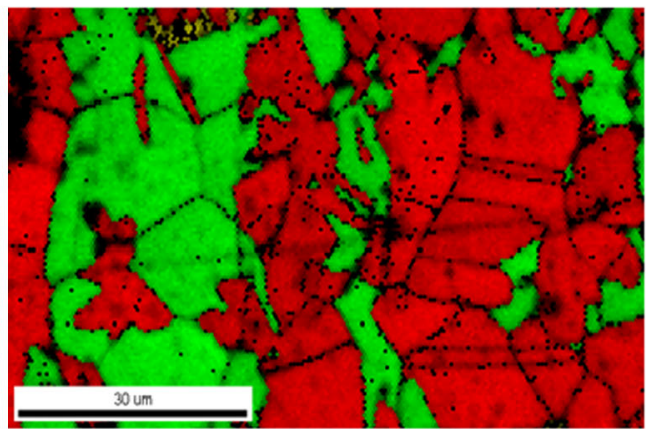

(d)

regions correspond to ferromagnetic phases (i.e. ferrite), and light regions to paramagnetic phases (i.e. austenite, sigma phase and chi phase. $\mathbf{c}$ and $\mathbf{d}$ are the EBSD phase maps, where austenite is red, ferrite is green and sigma phase is yellow (Color figure online)
Table 4 Area percentages of phases in 2205 duplex steel under alternative ageing conditions

\begin{tabular}{lccrrr}
\hline Type & Temperature $\left({ }^{\circ} \mathrm{C}\right)$ & Phase & \multicolumn{4}{l}{ Ageing time $(\mathrm{h})$} \\
\cline { 3 - 5 } & & & $1 / 2$ & \multicolumn{1}{c}{5} & 50 \\
\hline Experimentally measured & 750 & Ferrite & 47.7 & 29.5 & 7.9 \\
& \multirow{2}{*}{850} & Sigma & 2.1 & 4.2 & 17.8 \\
& & Ferrite & 32.2 & 0.3 & 1.4 \\
& & Sigma & 5.3 & 22.7 & 21.3 \\
\hline
\end{tabular}

All experimental values determined through 'large area' EBSD mapping
$5.6 \mu \mathrm{m}$ dia. $/ 25 \mu \mathrm{m}^{2}$ after $10 \mathrm{~h}$. There was a less significant change in size for subsequent ageing periods, with the (few) remaining ferrite grains having a mean grain size of approximately $4.4 \mu \mathrm{m}$ dia. $/ 15 \mu \mathrm{m}^{2}$, which can be accredited to the slower rate of formation of sigma due to the remaining ferrite becoming impoverished in chromium. The mean size of austenite grains remains approximately constant (13.9-16.0 $\mu \mathrm{m}$ dia./150-200 $\mu \mathrm{m}^{2}$ ), however, the range of the values shows an increase in both large $\left(>16.0 \mu \mathrm{m}\right.$ dia. $\left./ 200 \mu \mathrm{m}^{2}\right)$ and small $(<11.3 \mu \mathrm{m}$ dia./ $100 \mu \mathrm{m}^{2}$ ) grains indicating coarsening and reflecting the nucleation of secondary austenite grains as a product of ferrite decomposition.

Figure 5 shows regions mapped with MFM, where the light (golden) phase is austenite and the darker (brown/ black) phase is ferrite; the intensity of the signal depends on the magnitude of interaction between the probe tip and the specimen. Thus, paler ferrite grains correspond to subsurface grains which have their magnetic signal attenuated by the intervening austenite or sigma phase [20]. The ripples in the ferrite regions are caused by the interaction of the magnetic field lines with the MFM probe tip, and therefore different line orientations correspond to different magnetic fields or domains. The importance of the ability to measure to approximately $120 \mathrm{~nm}$ beneath the specimen surface [20] with this technique is shown in the maps collected at longer ageing periods, where the sub-surface ferrite is indistinguishable within the EBSD images [20].

The sigma-phase grains show no preferred specific orientation relationship with neighbouring ferrite grains. The 
Fig. 4 EBSD phase maps for thermally aged $\left(800^{\circ} \mathrm{C}\right)$ duplex steel. a Unaged (ferrite and austenite), b $1 \mathrm{~h}$ (ferrite, austenite and sigma phase) and c $100 \mathrm{~h}$ (austenite, sigma phase and trace ferrite). The colour key in the EBSD maps is red for austenite, green for ferrite and yellow for sigma (Color figure online) (a)

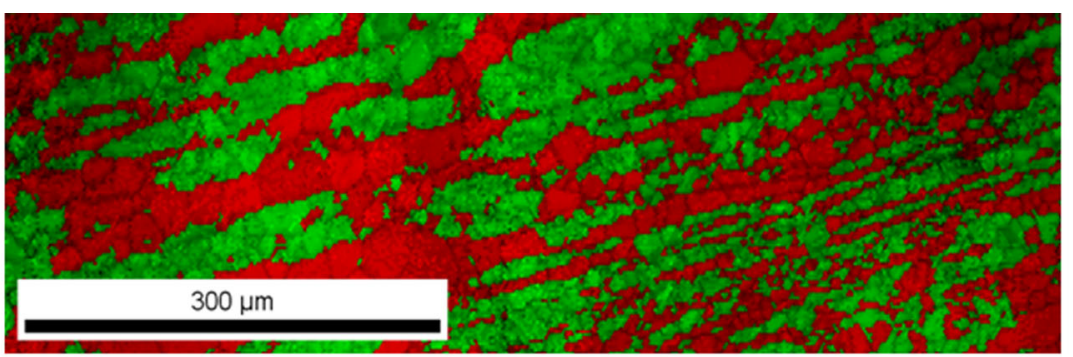

(b)

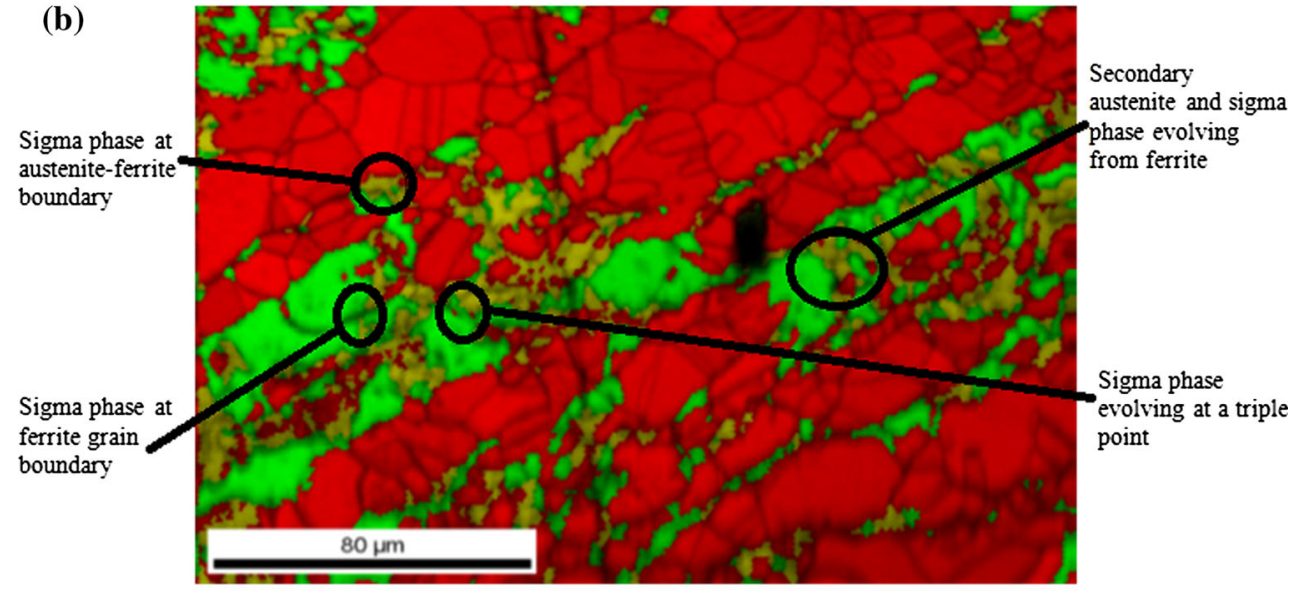

(c)

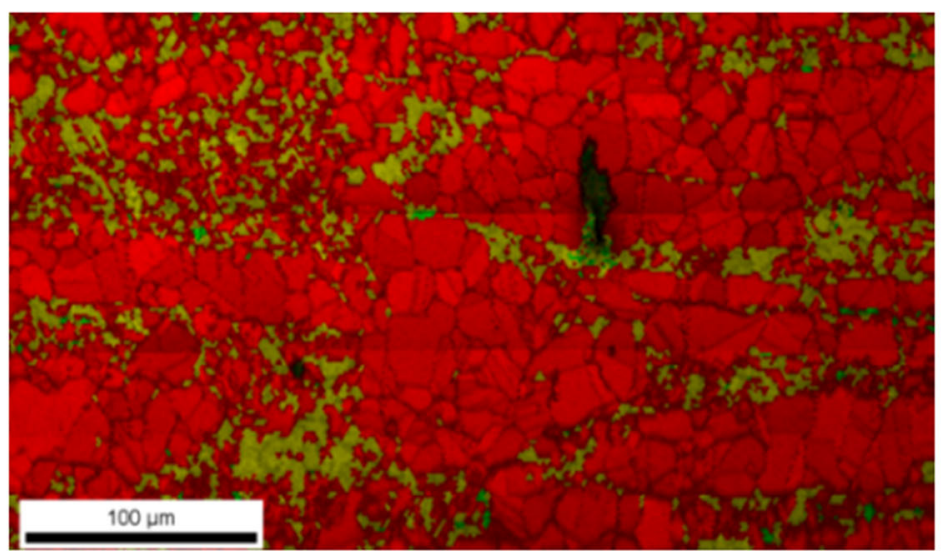

phase-specific EBSD IPF orientation maps (Fig. 6) show that the multiple sigma grains that border a ferrite grain have different orientations. The IPF maps also show that the ferrite has a depletion in $<111>$-oriented grains, which becomes particularly apparent using the inverse pole figure plots, Fig. 6 .

The austenite inverse pole plot for a specimen aged at $800{ }^{\circ} \mathrm{C}$ for $1 \mathrm{~h}$ (Fig. 7a) shows a random distribution of orientations, whilst the ferrite plot for the same conditions shows a more limited distribution of orientations (Fig. 7b) being centred around the $<001>$ and $<101>$ orientations. The low volume fraction of sigma phase present under these ageing conditions in the sampled region gives an under representative distribution of orientations, Fig. 7c. EBSD maps and the corresponding inverse pole plots taken from other regions within the specimen have a more homogeneous distribution of orientations for sigma phase. Material aged for $10 \mathrm{~h}$ at $800{ }^{\circ} \mathrm{C}$ showed a similar random distribution of orientations for austenite grains (Fig. 6d), the low volume fraction of ferrite resulted in a very limited range of orientations (Fig. 6e) and a more representative distribution of orientations for sigma phase, Fig. 7f.

Using a system with coincident EDX and EBSD detection, it was possible to map regions for both elemental composition and microstructure. The EBSD images in Fig. $8 \mathrm{a}$ and $\mathrm{b}$ show the phase distributions after $30 \mathrm{~min}$ and $10 \mathrm{~h}$. The collected maps (Fig. 8) show the expected redistribution of $\mathrm{Cr}$ and $\mathrm{Mo}$ [5] during ageing; the sigma grains are enriched in $\mathrm{Cr}$ compared to austenite and ferrite (Fig. 8c, d); and sigma phase and ferrite have similar 
Fig. 5 MFM maps showing the distribution of ferrite in specimens aged at $800{ }^{\circ} \mathrm{C}$ for differing lengths of time. a Unaged material, showing the distinctive banded structure and b material aged for $40 \mathrm{~h}$. In both maps, ferrite appears as brown, with the relative intensity of shading corresponding to the magnitude of the signal. The ripples in the ferrite signals are caused by interactions with the magnetic field lines. Thus, the faint brown features in (b) are grains which are beneath the specimen surface (Color figure online)
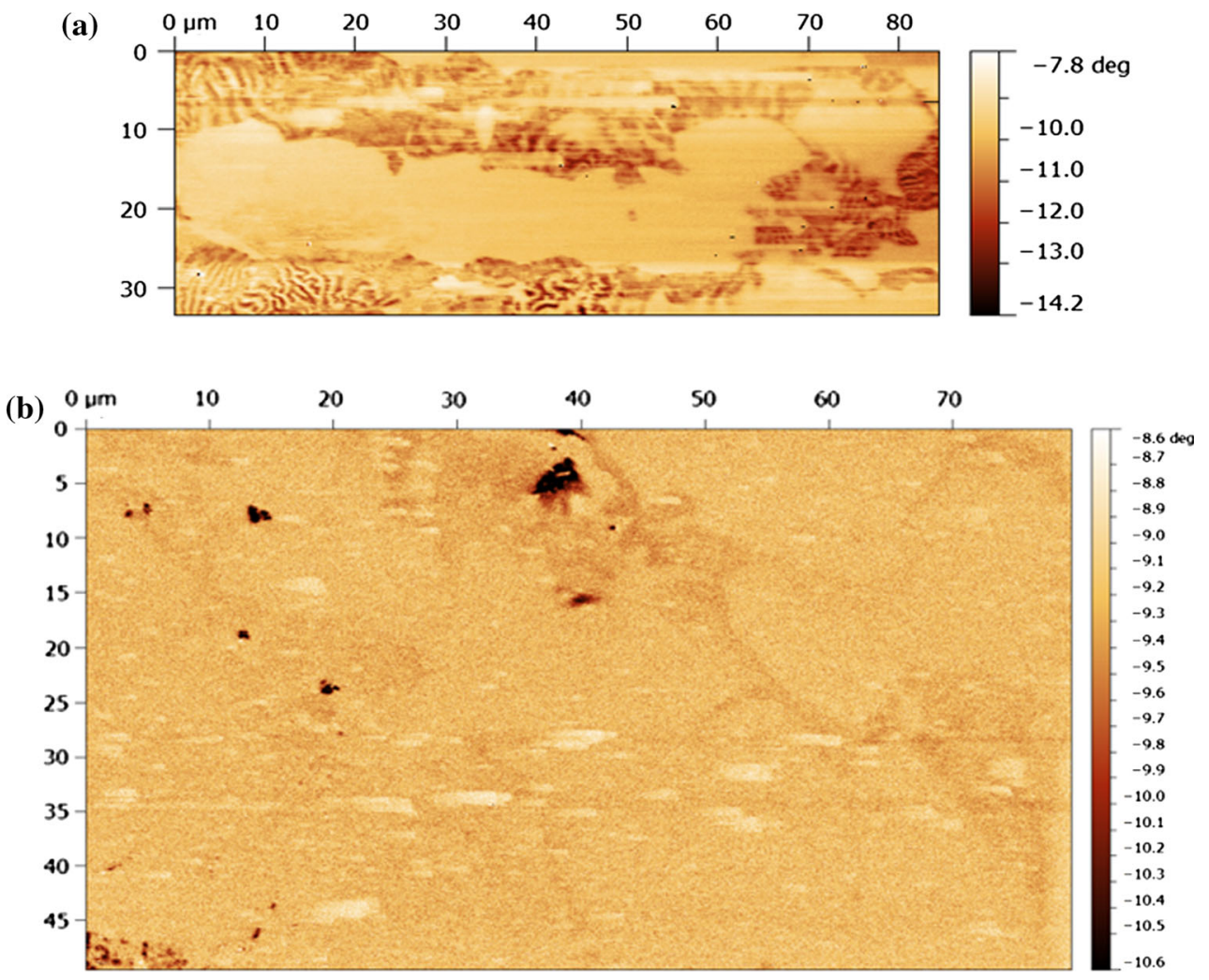

distributions of $\mathrm{Cr}$ (Fig. 8e, f). No significant concentration gradients were present in the elemental images of ferrite grains (e.g. a degree of enrichment in parts of ferrite grains bordering sigma grains), with redistribution between elemental concentrations at phase boundaries being distinct as opposed to diffuse. This indicates that concentration gradients possibly exist at a very fine length scale $(<1 \mu \mathrm{m})$, which is beyond the resolution of SEM-EDX. At longer ageing periods, regions of $\mathrm{Cr}$ - and Mo-depleted ferrite can be observed bordering (and in some cases almost surrounded by) sigma grains, shown as white circled regions in Fig. 8c and e. Ferrite grains with $\mathrm{Cr}$ and Mo levels lower than the neighbouring austenite become more common at increasing ageing periods, several grains are circled in black in Fig. 8d and f.

\section{Discussion}

The present results of thermal ageing of the duplex 2205 stainless steel show that the precipitation of sigma phase occurs within ferrite and at the austenite-ferrite interphase boundaries, by the mechanism $\delta$-ferrite $\rightarrow$ sigma phase + secondary austenite. This is summarised schematically in Fig. 9a: austenite grains are red, ferrite grains are green and sigma phase is yellow. Grey grain boundaries and hatched regions show grain locations at a later ageing time, $\mathrm{t}_{2}$.
In Fig. 9a, a sigma-phase grain has nucleated at a highenergy triple point $[4,7]$ (as the schematic is two dimensional, these can be either grain edges or nodes in 3D [7, 8, 38]) and its location is shown at $t_{1}$. After further ageing, $t_{2}$, the sigma-phase precipitate grows to occupy the yellow hatched region. This transformation results in the $\mathrm{Cr}$ and Mo diffusing from a neighbouring region of ferrite, destabilising it and leading to the formation of secondary austenite, the red hatched region in Fig. 9a. Figure 9b shows this phase transformation process occurring at an austenite-ferrite phase boundary in greater detail, using the same colour coding. The sigma-phase precipitate grows preferentially into the ferrite due to favourable kinetics of $\mathrm{Cr}$ and Mo diffusion [5]. Again, the Cr- and Mo-depleted ferrite is destabilised and forms secondary austenite.

The sigma-phase precipitates show no favoured nucleation orientation relationship relative to the parent ferrite grain. This indicates that the energy benefits arising from minimising the interfacial energy by nucleation in a given orientation is not a controlling factor in the nucleation of sigma grains under these ageing conditions. Due to the readier diffusion of $\mathrm{Cr}$ and Mo in ferrite [5], the sigma phase grows preferentially into the ferrite rather than into the austenite.

EDX maps of the unaged steel showed no significant inhomogeneities in the distribution of Mo or $\mathrm{Cr}$ within the ferrite bands, or at ferrite-austenite grain boundaries. There 
Fig. 6 Phase-specific inverse pole figure (IPF) orientation maps for steel aged at $800{ }^{\circ} \mathrm{C}$ for $1 \mathrm{~h}$. a IPF orientation key, b sigma-phase-specific map, c ferrite-specific map and d austenite-specific map (a)

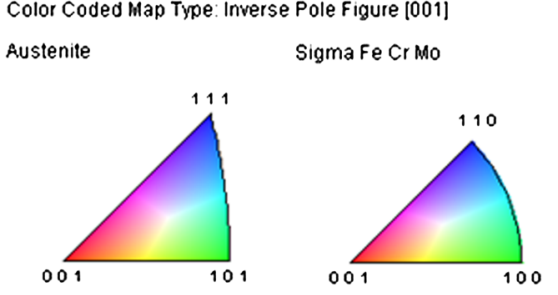

Ferrite

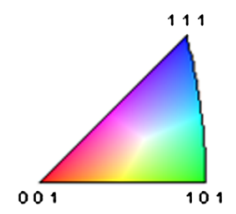

(c)

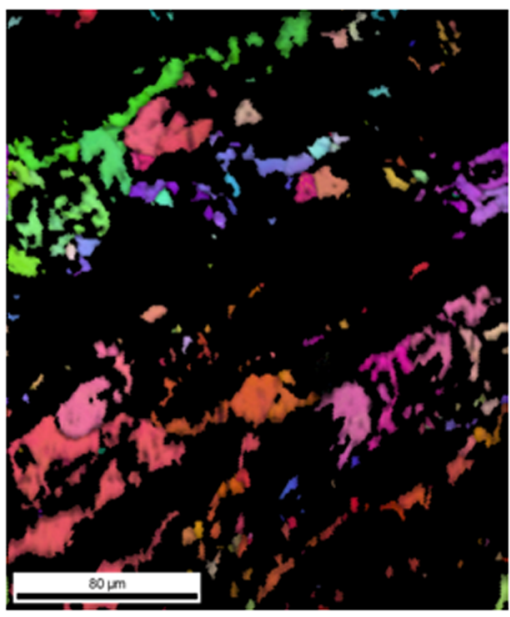

(b)

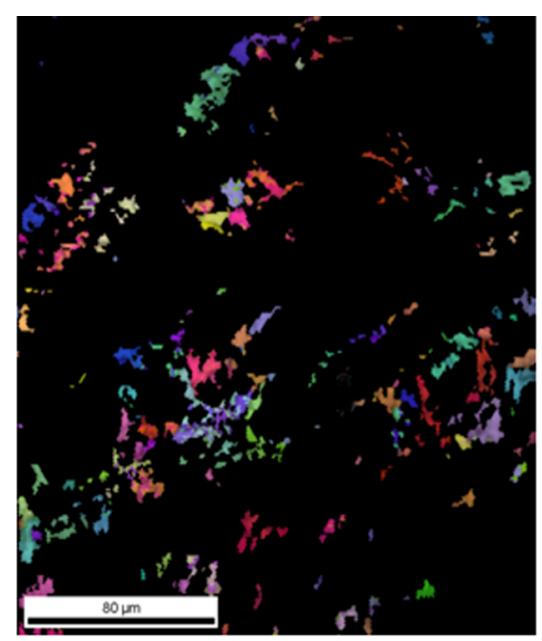

(d)

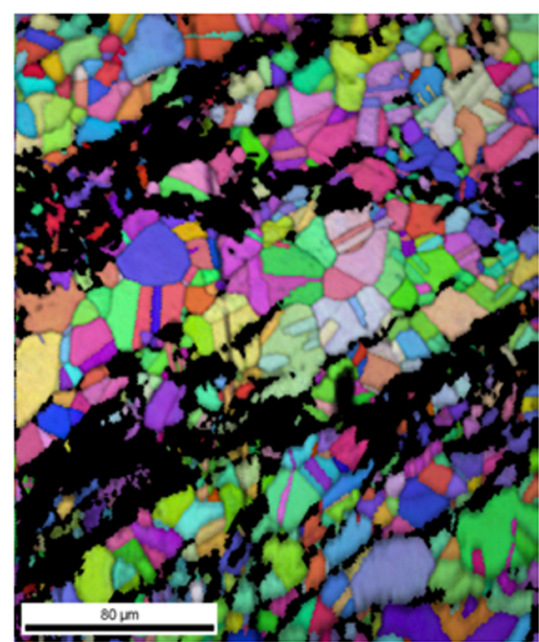

Fig. 7 EBSD inverse pole figure (IPF) maps showing the distribution of grain orientations for the phases for different ageing durations at $800{ }^{\circ} \mathrm{C}$. a austenite, $\mathbf{b}$ ferrite and $\mathbf{c}$ sigma phase after ageing for $1 \mathrm{~h}$ and $\mathbf{d}$ austenite, $\mathbf{e}$ ferrite and $\mathbf{f}$ sigma phase after ageing for $10 \mathrm{~h}$. Note the depletion of [111] oriented grains present in (b)
[001]

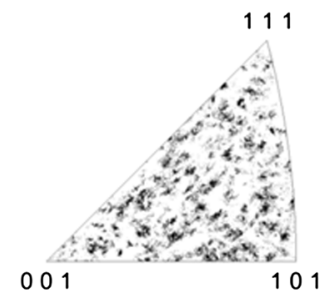

(a)

[001]
[001]

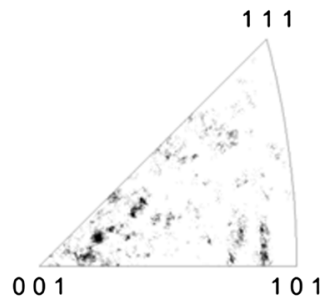

(b)

[001]
[001] (c)

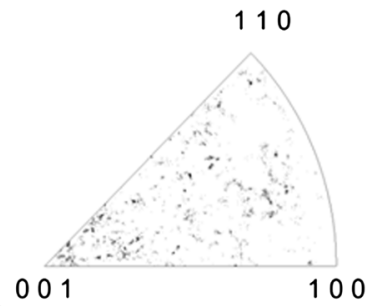

[001] (d)

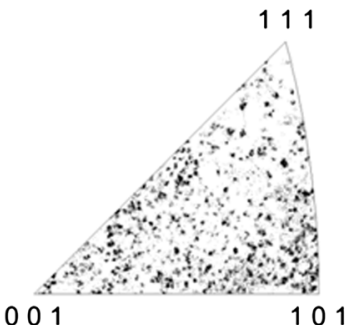

101

(e)

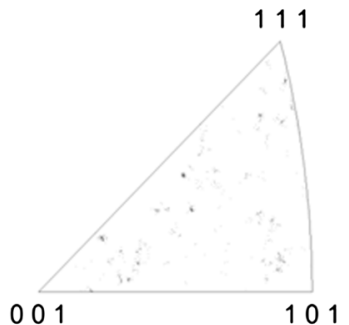

$001 \quad 101$

(f)

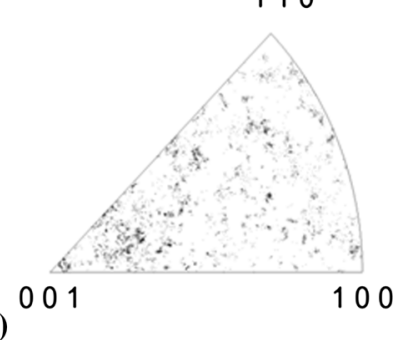


Fig. 8 Combined EBSD and EDX maps for steel aged at $800^{\circ} \mathrm{C}$. a EBSD map of $30 \mathrm{~min}$ region, b EBSD map of $10 \mathrm{~h}$ region, $\mathbf{c}$ and $\mathbf{d}$ Mo intensity maps, $\mathbf{e}$ and $\mathbf{f} \mathrm{Cr}$ intensity maps. In the EBSD maps, red corresponds to austenite, green to ferrite and yellow to sigma. In the elemental maps, the brighter shades correspond to an enrichment of the element. Note that sigma is enriched in both $\mathrm{Cr}$ and Mo compared to ferrite. Note the depletion of Mo in the ferrite grains (and edges regions of austenite grains) bordering sigma phase, circled in white in $(\mathbf{a}, \mathbf{c}, \mathbf{e})$; and the low $\mathrm{Cr}$, low $\mathrm{Mo}$ ferrite grains circled in black in (b, f) and light blue in

(d) (Color figure online)

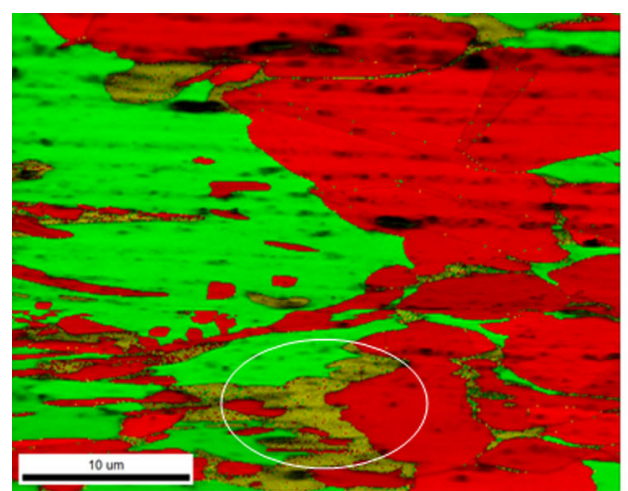

(a)

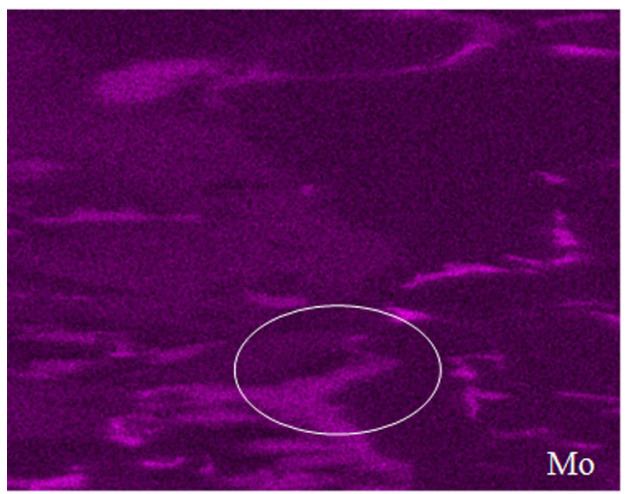

(c)

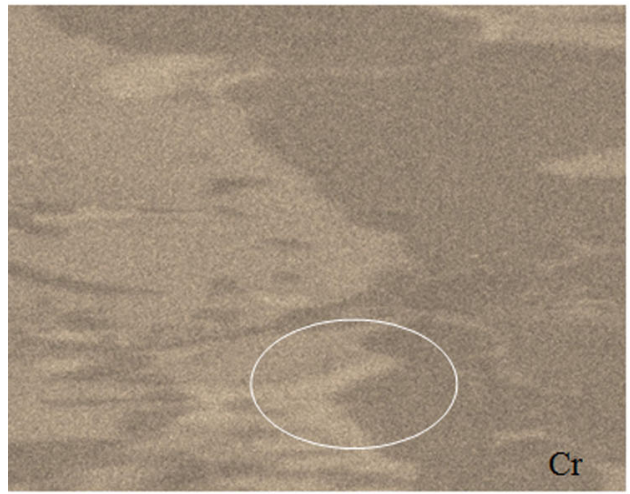

(e)

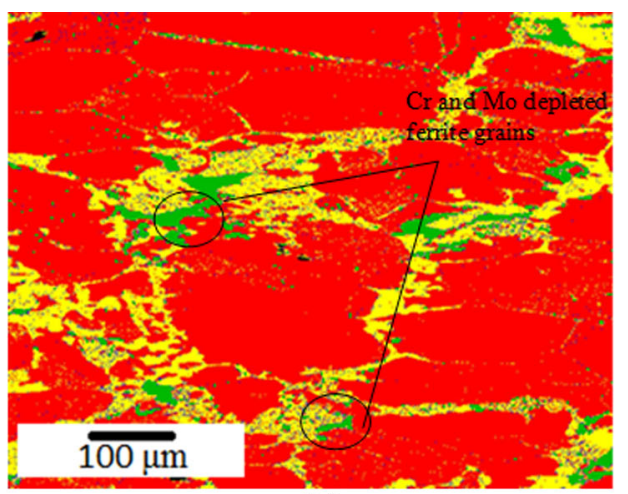

(b)

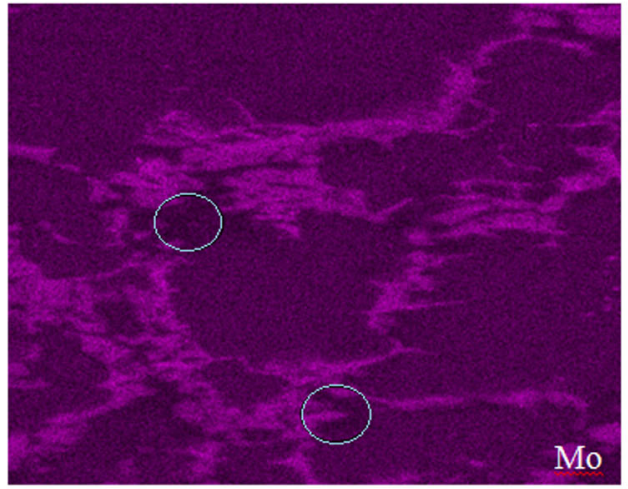

(d)

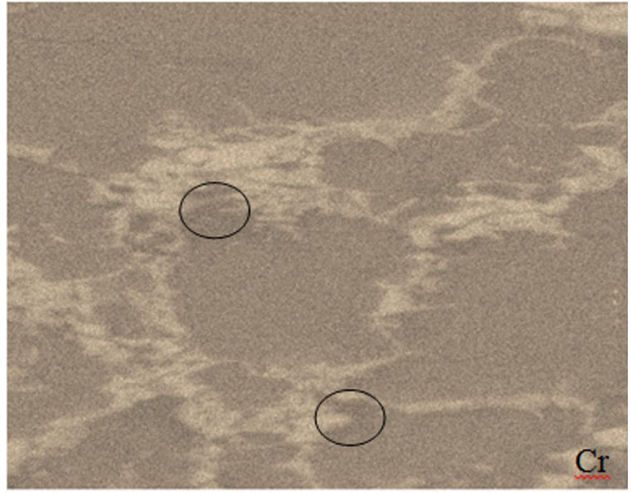

(f) is no evidence for pre-existing micro-scale fluctuations in composition which could act as precursor sites for sigmaphase nucleation. As such, the sites at which sigma phase nucleates must be dependent on preferential energetics and diffusion pathways. The correlated EBSD-EDX maps show that the sigma phase has a broadly comparable $\mathrm{Cr}$ content to ferrite, but is significantly enriched in Mo. As ferrite is enriched in these bcc elements compared with the austenite, the sigma phase grows preferentially into the ferrite [4], Fig. 8b.

The mean and standard deviation of the sigma-phase precipitate size remains approximately constant throughout ageing, supporting a continuing process of nucleation and diffusional growth. This is followed by slow diffusional growth since the secondary austenite formed will be impoverished in $\mathrm{Cr}$, and the rate of diffusion of $\mathrm{Cr}$ through austenite or along grain boundaries is slow [8]. Material aged for longer times will have reduced concentration gradients of $\mathrm{Cr}$ and Mo which would favour an increased rate of growth over that of nucleation. This is reflected by the gradual increase in the mean sigma-phase grain size. The gradual nature of this increase implies a continuation of sigma-phase grain nucleation until comparatively late in the ageing process, arising from the relative concentration of chromium present in the steel.

Although there is the potential for the ferrite quantifications achieved through EBSD maps to contain a contribution from chi phase, the EBSD-MFM comparisons 
Fig. 9 Schematic diagram showing a sigma-phase nucleation and growth in ferrite bands during thermal ageing of 2205 DSS and $\mathbf{b}$ the local growth of sigma phase at the austenite-ferrite interphase boundary. Lines are shown to emphasise the trends in the volume fraction of the phases. The predicted sigma-phase line is based on the predictions at the points shown, and does not correspond to a full range prediction (a)

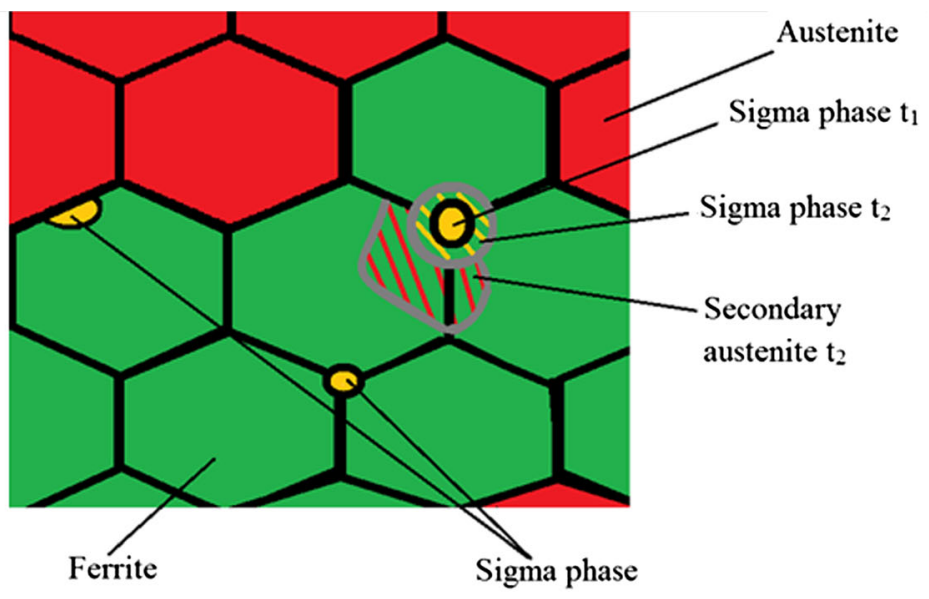

(b)

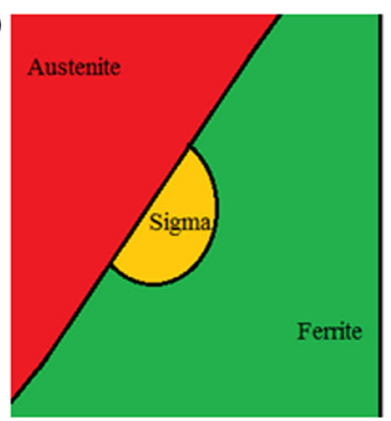

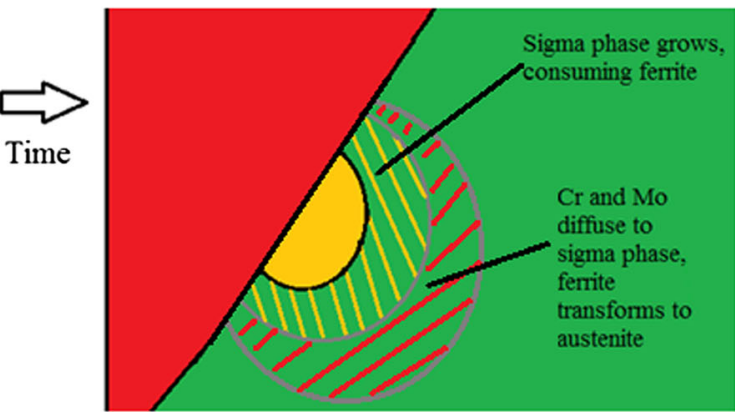

showed this contribution to be negligible in the regions imaged. As such, any contributions made by chi phase to the volume percentage measured for ferrite are covered by the existing calculated error.

The JMatPro computer model predictions for the evolution of sigma phase during ageing at $800{ }^{\circ} \mathrm{C}$ show a very close correlation to the experimental data measured throughout the ageing period, Fig. 1. A comparison between the JMatPro predictions and the measured phase percentages at 750 and $850{ }^{\circ} \mathrm{C}$ is shown in Fig. 1. In this case, the correlations are good, except for the $5 \mathrm{~h}$ result where the experimental data differ slightly from the prediction. The measured result falls short of the prediction for the $750{ }^{\circ} \mathrm{C}$ and is exceeded for $850{ }^{\circ} \mathrm{C}$. As these are periods of rapid change, it is likely that the discrepancy is due to regional variations and therefore sampling error in the experimental results. As the sigma phase evolves, the ferrite is converted to secondary austenite. The computer model does not give any prediction for the rate of ferrite dissolution or secondary austenite evolution (which could be used to determine the rate of ferrite consumption).

This study has also shown that MFM, a novel technique for materials characterisation [20], gives volume percentages comparable to those measured by a wide range of techniques in both ferrite-rich and ferrite-poor environments. When the same region has been imaged with multiple techniques, a very good correlation has been observed between the regions. Given the paramagnetic nature of chi phase, MFM does not suffer the potential to mis-identify chi phase as ferrite. MFM and EBSD maps from several regions in specimens aged under conditions expected to produce chi phase were compared, showing that chi-phase is not present in the material. As such unambiguous differences in the measured quantities of ferrite are achieved.

The correction factor to convert the MFM volume percentages to area percentages, as proposed by Warren et al. [20], has been assessed as the potential source of the difference between the EBSD and MFM ferrite measurements. When the proportion of ferrite is small, the depth sensitivity of MFM becomes increasingly significant. The technique will identify sub-surface grains which would not be detected by EBSD, giving a higher measure of the quantity of ferrite in the material. The correction factor proposed by Warren et al. assumed that ferrite grains were typically grouped in bands, with potential sub-surface structure visible over half of the grains circumference, with the remaining signal being shielded by neighbouring ferrite grains. It was also assumed that the number of grains in the centre of the ferrite bands would equal the number of 'stray' isolated ferrite grains, and thus the sub-surface contributions would be approximately equivalent. As such under early ageing conditions, these assumptions are generally valid and the correction factor can be considered representative. However, for the later stages of ageing, 
where the ferrite bands have degraded leaving isolated ferrite grains dispersed throughout the material, this is no longer true. Assuming that the ferrite grains have no shielding due to neighbours, then a correction factor to fully address the effect of sub-surface measurement becomes

Ratio $=\frac{\pi\left(\frac{7.5}{2}\right)^{2}}{\pi\left(\frac{7.5+0.24}{2}\right)^{2}}=0.94$

Thus, the error resulting from using the original correction factor $(0.97$ [20]) will be minimal (3\% of the present value). This small difference will contribute to the difference between the ferrite quantifications by the different techniques. Although the dissolution of ferrite can be used as a general indication of the evolution of sigma phase, it is not possible to compare the data with readily available commercial models.

The kinetics of sigma-phase precipitation is controlled by the diffusion of $\mathrm{Cr}$ and Mo [4, 5], and this is supported by the microstructural observations discussed previously. It is possible to determine a rate of reaction for the formation of sigma phase at the different ageing temperatures. Burke proposes a variant of the Johnson-Mehl equation [39] for determining the empirical rate of reaction for heterogeneous phase changes in metals:

$\ln \left(\frac{1}{1-y}\right)=(k t)^{n}$

where $y$ is the fraction of sigma phase formed (relative to the equilibrium volume fraction of sigma phase) at time $t$, $k$ is the empirical rate constant and $n$ is the time exponent. The time exponent is selected based on the shape of the sigmoidal transformation curve, and for this reaction $n=1$. A $y$ value of 0.5 was used for consistency across the temperature range, and the results are given in Table 5.

The rates of reaction for both the predicted and measured evolution of sigma phase at $800{ }^{\circ} \mathrm{C}$ show good correlation, matching the phase volume fraction predictions. The rates for sigma-phase evolution at $750{ }^{\circ} \mathrm{C}$ both differ significantly, reflecting the difference in the predicted and measured volume fractions at $5 \mathrm{~h}$.

Table 5 Predicted and experimentally measured rate of reactions

\begin{tabular}{lll}
\hline Method & Temperature $\left({ }^{\circ} \mathrm{C}\right)$ & $k\left(\mathrm{~h}^{-1}\right)$ \\
\hline JMatPro computer model & 750 & 0.12 \\
& 800 & 0.22 \\
& 850 & 0.58 \\
Experimental & 750 & 0.04 \\
& 800 & 0.28 \\
& 850 & 1.38 \\
\hline
\end{tabular}

The measured and predicted activation energies can be calculated from the rate of reaction [31].

$k=A e^{-E_{a} / R T}$,

where $k$ is the rate of reaction, $E_{a}$ is the activation energy, $R$ is the gas constant and $T$ is the temperature. Taking logarithms gives

$\log k=\log A-{ }^{-} E_{a} / R T$.

Thus, the gradient of a plot of $\log k$ against $1 / T$, Fig. 10, is the activation energy $E_{a} / R$. Hence the precipitation of sigma phase has an experimentally derived activation energy of $-1180 \mathrm{~J} \mathrm{~mol}^{-1}$; compared to the JMatPro prediction of $-522 \mathrm{~J} \mathrm{~mol}^{-1}$.

The activation energy used in the JMatPro computer model is a concentration-dependant diffusional activation energy, calculated from literature data [40]. The difference between the experimental and predicted activation energies is likely to be due to the regional variations in the experimentally measured volume fraction of sigma phase and the specific diffusion pathways of all bcc atom species in this duplex stainless steel. With this taken into consideration, the correlation between the measured and predicted activation energies is acceptable for this diffusion controlled process.

\section{Conclusions}

We have used a set of complimentary materials analysis approaches to quantify the evolution of sigma-phase precipitates in 2205 super duplex stainless steel. Our observations concur with the theory that precipitate evolution occurs through both nucleation and diffusional growth throughout the ageing period, as a result of the mechanism: $\delta$-ferrite $\rightarrow$ sigma phase $+\mathrm{Cr}$ - and Mo-depleted secondary austenite. Sigma precipitates nucleate at high-energy grain boundary sites within the ferrite and austeniteferrite interphase boundaries. The initial banded ferrite microstructure was partially preserved following extended ageing, but not the crystallographic texture. The present EBSD measurements of sigma-phase precipitates showed no preferential orientation, suggesting that the minimisation of energy due to crystallographic misorientation plays a minimal role in sigma-phase nucleation. Ferrite grains were preserved after $100 \mathrm{~h}$ at $800{ }^{\circ} \mathrm{C}$, at which stage the volume fraction of sigma phase had stabilised. These ferrite grains were often significantly depleted in $\mathrm{Cr}$ and $\mathrm{Mo}$, which would retard the rate of reaction.

EBSD and MFM have been shown to give comparable measure of the proportion of ferrite for a range of heat treatment conditions. Although quantification of the amount of ferrite by EBSD has the potential to be 
Fig. 10 Graph plotting 1/absolute temperature against rate of reaction to enable the calculation of the experimental and predicted activation energy for the precipitation of sigma phase during the thermal ageing of 2205 DSS

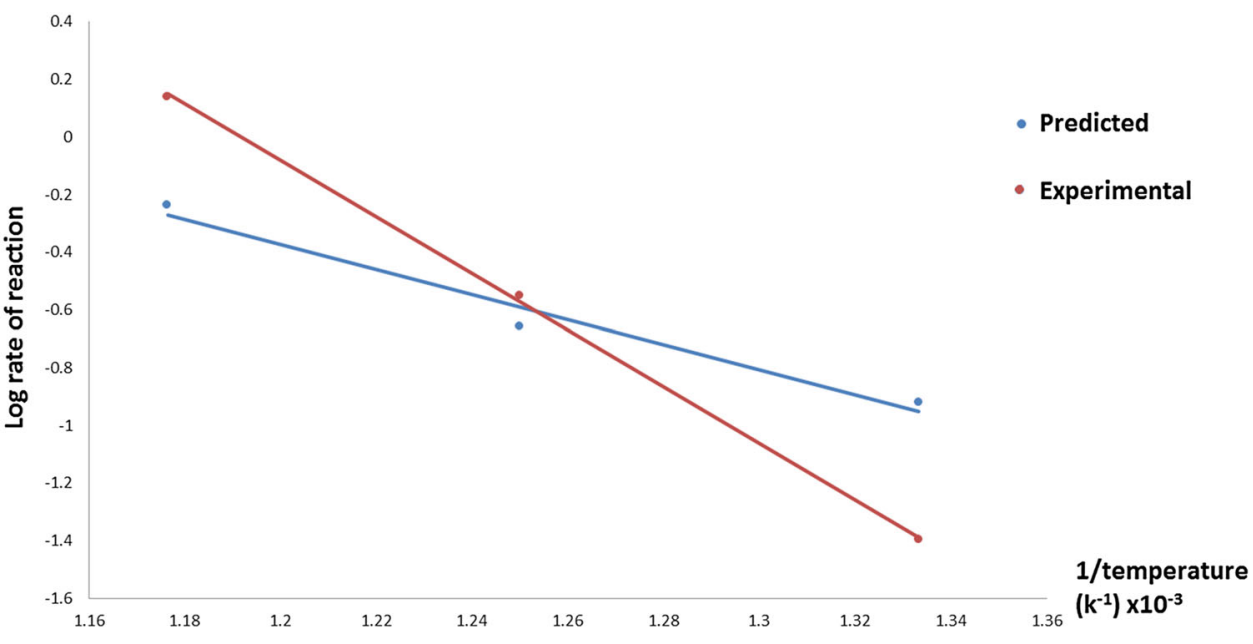

influenced by the presence of chi phase due to misidentification of the BCC structure, this is not the case with MFM. Direct comparison of several regions of a sample with both techniques showed no chi phase present. As such, the small difference in the quantified proportion of ferrite present between the techniques is attributed to sampling effects and the lack of suitability of the correction factor proposed by Warren et al. [20] for low ferrite environments. A new correction factor is proposed.

The model predictions produced by JMatPro match the mechanisms and volume fractions for the evolution of sigma phase during ageing at $750-850{ }^{\circ} \mathrm{C}$. The rates of sigma-phase precipitation at 750 and $850{ }^{\circ} \mathrm{C}$ were found to differ, as did the activation energies. This is due to the regional variations in the distribution of ferrite. Component suitability assessments based on JMatPro predictions of phase evolution are thus likely to be accurate over longer periods where close-to equilibrium conditions dominate.

Acknowledgements The authors thank Engineering and Physical Science Research Council (EPSRC) PROMINENT consortium for the funding for this research; Dr. Jean-Phillipe Schille of Sente Software for his assistance with the JMatPro calculations; Outokumpu steel for provision of the duplex steel; Dr. S Hall of the University of Bristol School of Chemistry for access to a substitute furnace; and K. Abbott of EDF Energy for his assistance with the magneprobe measurements.

Funding This study was funded by the Engineering and Physical Sciences Research Council.

\section{Compliance with ethical standards}

Conflict of interest Zhanli Guo is an employee of Sente Software, the manufacturers of JMatPro. There are no further conflicts of interest to report.

Open Access This article is distributed under the terms of the Creative Commons Attribution 4.0 International License (http://creativecommons.org/licenses/by/4.0/), which permits unrestricted use, distribution, and reproduction in any medium, provided you give appropriate credit to the original author(s) and the source, provide a link to the Creative Commons license, and indicate if changes were made.

\section{References}

1. Pohl M, Storz O, Glogowski T (2007) Effect of intermetallic precipitations on the properties of duplex stainless steel. Mater Charact 58:65-71

2. Topolska S, Labanowski J (2009) Effect of microstructure on impact toughness of duplex and super duplex stainless steel. J Achiev Mater Manuf Eng 36:142-149

3. Keshmiri H, Momeni A, Dehghani K, Ebrahimi GR, Heidari G (2009) Effect of aging time and temperature on mechanical properties and microstructural evolution of 2205 ferritic-austenitic stainless steel. J Mater Sci Technol 25:597-602

4. Hsieh C, Wu W (2012) Overview of intermetallic sigma $(\sigma)$ phase precipitation in stainless steels. ISRN Metall 2012:16 pp

5. Sieurin H, Sandström R (2007) Sigma phase precipitation on duplex stainless steel 2205. Mater Sci Eng A 444:271-276

6. Degtyareva VF, Dubrovinsky L, Kurnosov A (2009) Structural stability of the sigma phase $\mathrm{FeCr}$ under pressure up to $77 \mathrm{GPa}$. J Phys 21:075706 (4 pp)

7. Martins M, Casteletti LC (2009) Sigma phase morphologies in cast and aged super duplex stainless steel. Mater Charact 60:792-795

8. Magnabosco R (2009) Kinetics of sigma phase formation in a duplex stainless steel. Mater Res 12:321-327

9. Ryde L (2006) Application of EBSD to analysis of microstructures in commercial steels. Mater Sci Technol 22:1297-1306

10. Sato YS, Nelson TW, Sterling CJ, Steel RJ, Pettersson CO (2005) Microstructure and mechanical properties of friction stir welded SAF 2507 super duplex stainless steel. Mater Sci Eng A 397:376-384

11. Flewitt PEJ, Wild RK (2003) Physical methods for materials characterisation, 2nd edn. IOP Publishing, Bristol

12. Koblischka MR, Hartmann U (2003) Recent advances in magnetic force microscopy. Ultramicroscopy 97:103-112

13. Martin Y, Wickramasinghe HK (1987) Magnetic imaging by "force microscopy" with $1000 \AA$ resolution. Appl Phys Lett $50: 1455-1457$

14. Hartmann U (1999) Magnetic force microscopy. Annu Rev Mater Sci 29:53-87

15. Magnetic properties of stainless steel (2000) British stainless steel association's stainless steel advisory service. Sheet Number 2(81):1-2 
16. Kabliman EA, Mirzoev AA, Udovskii AL (2009) First-principles simulation of an ordered sigma phase of the $\mathrm{Fe}-\mathrm{Cr}$ system in the ferromagnetic state. Phys Met Metall 108:435-440

17. Dias A, Andrade MS (2000) Atomic force and magnetic force microscopies applied to duplex stainless steels. Appl Surf Sci 161:109-114

18. Gheno SM, Santos FS, Kuri SE (2008) Probing the duplex stainless steel phases via magnetic force microscopy. J Appl Phys 103:0539061-0539065

19. Gadelrab KR, Li G, Chisea M, Souier T (2012) Local characterisation of austenite and ferrite phases in duplex stainless steel using MFM and nano indentation. J Mater Res 27:1573-1579

20. Warren AD, Harniman RL, Collins AM, Davis SA, Younes CM, Flewitt PEJ, Scott TB (2015) Comparison between magnetic force microscopy and electron back-scatter diffraction for ferrite quantification in type 321 stainless steel. Ultramicroscopy 148:1-9

21. Padhilha AF, Rios PR (2002) Decomposition of austenite in Austenitic stainless steels. ISIJ Int 42:325-337

22. Escriba DM, Materna-Morris E, Plaut RL, Padhilla AF (2009) Chi-phase precipitation in a duplex steel. Mater Charact 60:1214-1219

23. Sourmail T (2001) Precipitation in creep resistant austenitic steels. Mater Sci Technol 17:1-14

24. Shankar P, Shaikh H, Sivakumar S, Venugopal S, Sundararaman D, Khatak HS (1999) Effect of thermal aging on the room temperature thermal aging properties of AISI type 316LN stainless steel. J Nucl Mater 264:29-34

25. Stauffer AC, Koss DA, McKirgan JB (2004) Microstructural banding and failure of a stainless steel. Metall Mater Trans A 35:1317-1324

26. Michalska J, Sozanska M (2006) Qualitative and quantitative analysis of $\sigma$ and $\chi$ phases in 2205 duplex stainless steel. Mater Charact 56:355-362

27. Calliari I, Zanesco M, Ramous E (2006) Influence of isothermal aging on secondary phases precipitation and toughness of a duplex steel SAF 2205. J Mater Sci 41:7643-7649. doi:10.1007/ s10853-006-0857-2
28. Ghosh SK, Mondal S (2008) High temperature ageing behaviour of a duplex stainless steel. Mater Charact 59:1776-1783

29. Nečas D, Klapetek P (2012) Gwyddion: an open-source software for SPM data analysis. Cent Eur J Phys 10(1):181-188

30. Johnson WA, Mehl RF (1939) Reaction kinetics in processes of nucleation and growth. Trans Am Inst Miner Metall Eng 135:416-458

31. Avrami M (1941) Granulation, phase change, and microstructure kinetics of phase change. III. J Chem Phys 9:177-184

32. Porter DA, Easterling KE (1981) Phase transformations in metals and alloys. Van Nostrand Reinhold, New York, pp 144-189

33. Li X, Miodownik AP, Saunders N (2002) Modelling of materials properties in duplex stainless steels. Mater Sci Technol 18:861-868

34. Saunders N, Guo Z, Li X, Midownik AP, Schillé JP (2003) Using JMatPro to model materials properties and behaviour. JOM 55:60-65

35. Guo Z, Saunders N, Miodownik AP, Schillé JP (2007) Quantification of high temperature strength of nickel-based superalloys. Mater Sci Forum 546-549:1319

36. Guo Z, Miodownik AP (2012) Modelling deformation-induced precipitation kinetics in microalloyed steels during hot rolling. Mater Sci Forum 706-709:2728-2733

37. Sente Software Ltd. (2014) Articles and papers. http://www.sen tesoftware.co.uk/downloads/articles-and-papers.aspx. Accessed 29 Aug 2014

38. Tavares SSM, Pardal JM, Guerreiro JL, Gomes AM, da Sliva MR (2010) Magnetic detection of sigma phase in duplex stainless steel UNS S31803. J Magn Magn Mater 322:L29-L33

39. Burke $\mathbf{J}$ (1965) The kinetics of phase transformations in metals, vol Chap 2.7, 1st edn. Pergamon Press Ltd, Oxford, pp 53-54

40. Askill J (1970) Tracer diffusion data for metals, alloys and simple oxides. Plenum Press, New York, pp 2-3 